\title{
Indakaterolis - greitai ir itin ilgai veikiantis beta 2 agonistas lètinei obstrukcinei plaučių ligai gydyti
}

\author{
Mindaugas Vaitkus \\ LSMU MA Pulmonologijos ir imunologijos klinika
}

Reikšminiai žodžiai: itin ilgai veikiantis beta 2 agonistas, lètinẻ obstrukcinė plaučių liga, gydymas inhaliuojamaisiais vaistais, indakaterolis, Onbrez ${ }^{\circledast}$ Breezhaler ${ }^{\oplus}$.

Santrauka. Onbrez ${ }^{\circledR}$ Breezhaler $^{\oplus}$ - pirmasis vieną kartą per parą vartojamas beta 2 agonistas, skirtas palaikomajam lètinės obstrukcinès plaučių ligos (LOPL) gydymui. Jis pasižymi itin greita veikimo pradžia - per 5 minutes nuo pirmosios dozės pavartojimo, ir 24 val. trunkančiu bronchus plečiančiu poveikiu. Rekomenduojama Onbrez ${ }^{\circledast}$ Breezhaler $^{\oplus}$ dozè - viena $150 \mu \mathrm{g}$ arba $300 \mu \mathrm{g}$ kapsulè vieną kartą per parą.

Šiame straipsnyje pateikiamų studijų duomenys įrodo, jog indakaterolis ženkliai, ilgam ir kliniškai reikšmingai pagerina plaučiu funkciją $\left(\mathrm{FEV}_{1}\right)$, sumažina dusulį ir pagerina bendrają sveikatos būklę lyginant su tiotropiu, salmeteroliu bei salmeterolio ir flutikazono sudètiniu vaistu.

Pagal šiuolaikines tarptautines klinikines LOPL gaires (GOLD) bronchodilatacija ir ligos simptomų kontrolé yra LOPL gydymo pagrindas. Rekomenduojama vartoti inhaliuojamuosius bronchus plečiančius vaistus: beta 2 agonistus ir anticholinerginius. Gydymas ilgo veikimo bronchus plečiančiais vaistais yra efektyvesnis nei trumpo veikimo. Inhaliuojamieji ilgo veikimo beta 2 agonistai, kaip antai salmeterolis ir formoterolis, išplečia bronchus apytiksliai 12 val., todèl juos reikia įkvėpti du kartus per dieną. Lètinių ligų gydymo veiksmingumas gali būti pagerintas paprastinant vaistų vartojimą, pavyzdžiui, suretinus jų vartojimą.

Indakaterolis yra vieną kartą per dieną inhaliuojamas ilgo veikimo bronchus plečiantis vaistas, skirtas LOPL gydyti. Indakaterolis - dalinis žmogaus beta 2 adrenoreceptorių agonistas, kurio poveikis panašus i beta 2 receptoriu, kaip ir formoterolio ar salmeterolio.

\section{GREITAS VEIKIMAS}

B. Balint su bendr. INSURE (INdacaterol: Starting quickly and Remaining Effective in COPD) tyrime lygino indakaterolio 150 ir $300 \mu \mathrm{g}$ veikimo pradžią su salbutamolio 200 $\mu \mathrm{g}$, salmeterolio ir flutikazono sudetinio vaisto $50 / 500 \mu \mathrm{g}$ ir placebo gydydami vidutinès ir sunkios stadijos LOPL sergančius pacientus.
Per pirmąsias 5 minutes nuo pirmos vaisto dozès lyginant indakaterolio 150 ir $300 \mu \mathrm{g}$ dozes su placebu nustatytas statistinis ir klinikinis $\mathrm{FEV}_{1}$ pagerèjimas $(\mathrm{p}=0,001)$ (atitinkamai indakaterolio $150 \mu \mathrm{g}-100 \mathrm{ml}$ (PI 70-130); indakaterolio $300 \mu \mathrm{g}-120 \mathrm{ml}$ (PI 90-150)). Abi indakaterolio dozès statistiškai reikšmingai padidino $\mathrm{FEV}_{1}$ 10 proc., 12 proc. ir 15 proc. arba 12 proc. ir $200 \mathrm{ml}$ nuo pradinio dydžio lyginant su placebu (1 pav.).

$\mathrm{FEV}_{1}$ per pirmąsias 5 minutes nuo pirmos vaisto dozès abiejose indakaterolio dozès grupèse buvo didesnis lyginant su salbutamoliu (10 ir $30 \mathrm{ml}$ atitinkamai indakaterolio 150 ir $300 \mu \mathrm{g}$ ) bei su salmeterolio ir flutikazono sudetiniu vaistu (atitinkamai $50 \mathrm{ml}, \mathrm{p}=0,003$ ir $70 \mathrm{ml}, \mathrm{p}<0,001$ ) (2 pav.). Tyrimo metu sunkių nepageidaujamų reiškinių nebuvo registruota.

Tiriant indakaterolio bronchodilatacinio poveikio greiti nustatyta, vieną kartą per parą vartojama Onbrez ${ }^{\circ}$ Breezhaler $^{\circ} 150 \mu \mathrm{g}$ bei $300 \mu \mathrm{g}$ dozè sukèlè stabiluc kliniškai reikšmingą plaučių funkcijos pagerèjimą (vertintas forsuoto iškvėpimo tūris per vieną sekundę, $F E V_{1}$ ), o vaisto poveikis truko daugiau kaip 24 valandas [16]. Poveikis pasireiške greitai (per 5 minutes po inhaliacijos, o $\mathrm{FEV}_{1}$ rodiklis padidejo $110-160 \mathrm{ml}$ lyginant su pradiniu) ir buvo panašus i $200 \mu$ g greitai veikiančio beta 2 agonisto salbutamolio poveikị bei statistiškai reikšmingai greitesnis už 


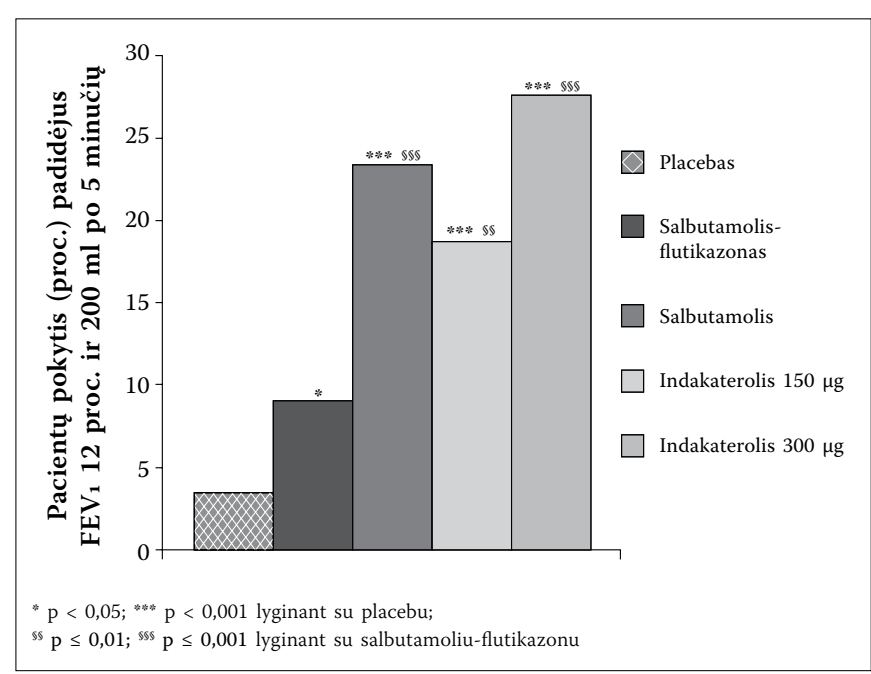

1 pav. Proporcijos pacientu, kuriems po pirmuju 5 minučiu FEV , padidejo 12 proc. ir $200 \mathrm{ml}$

salmeterolio ir flutikazono preparato (atitinkamai $50 \mu \mathrm{g}$ ir $500 \mu \mathrm{g}$ dozès) poveiki. Nusistovejjus pusiausvyrinei vaisto koncentracijai, vidutinis didžiausias $\mathrm{FEV}_{1}$ pagerèjimas, lyginant su pradiniu, buvo $250-330 \mathrm{ml}$.

Tyrimai rodo, kad 24 valandas trunkantis bronchus plečiantis $\mathrm{Onbrez}^{\circ} \mathrm{Breezhaler}^{\circ}$ poveikis gydymo laikotarpiu išlieka nuo pirmos dozès suvartojimo ištisus metus. Duomenų apie veiksmingumo mažèjimą (tachifilaksiją) nuolat vartojant vaistą negauta $[10,11]$.

Taigi vienkartinès 150 ir $300 \mu \mathrm{g}$ indakaterolio dozès bronchus plečiantis poveikis pasireiškia taip pat greitai kaip salbutamolio bei greičiau nei salmeterolio ir flutikazono sudètinio vaisto [1].

\section{EFEKTYVUMAS}

G. Feldman su bendr. įrodè, jog, vartojant indakaterolio $150 \mu \mathrm{g}$ vieną kartą per dieną, $\mathrm{FEV}_{1}$ reikšmingai padideja jau po pirmosios dozès $(\mathrm{p}<0,001)$. Indakaterolio grupejje statistiškai reikšmingas padidejęs $\mathrm{FEV}_{1}$ nustatytas pirmąją dieną ir po 12 savaičių lyginant su placebo grupe, atitinkamai $190 \pm 28 \mathrm{ml}(\mathrm{p}<0,001)$ ir $160 \pm 28 \mathrm{ml}(\mathrm{p}<0,001)$. Rytinè maksimali iškvepiamo oro srovè (PEF) praejjus 12 tyrimo savaičių indakaterolio $150 \mu \mathrm{g}$ grupeje buvo ženkliai didesnè nei placebo ryte ir vakare (atitinkamai $24,6 \pm 3,18$ ir 23,6 $\pm 3,11 \mathrm{l} / \mathrm{min}$.; $\mathrm{p}<0,001$ ). Tyrimo metu indakaterolio grupejje reikejo mažiau skubiosios pagalbos vaistụ lyginant su vartojusiais placebą (procentas dienų, kai nereikèjo skubiosios pagalbos vaistų, atitinkamai 54,63 \pm 1,942 ir 41,28 $\pm 2,004$; p < 0,001), o LOPL „blogos kontrolès dienu“" buvo net 22,5 proc. mažiau nei placebo grupejje (atitinkamai $31,19 \pm 1,500$ ir $40,24 \pm 1,554 ; \mathrm{p}<0,001$ ) [2].

Kitame 12 savaičių atsitiktinių imčių paralelinių grupių tyrime INSIST (angl. INdacaterol: investigating SuperiorIty vs SalmeTerol), kuri atliko S. Korn su bendr., buvo palygintas efektyvumas indakaterolio $150 \mu \mathrm{g}$, vartojamo vieną kartą per dieną, ir salmeterolio $50 \mu \mathrm{g}$, vartojamo du kartus per dieną. Svarbiausia vertinamoji baigtis -

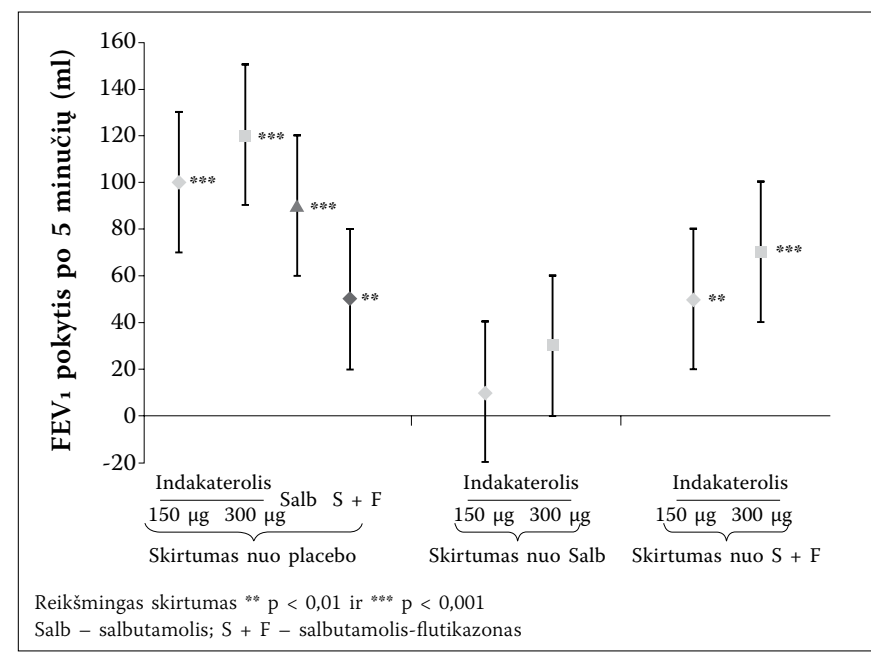

2 pav. $F E V_{1}$ pokytis indakaterolio $150 \mu \mathrm{g}$ bei $300 \mu \mathrm{g}$ ir placebo grupèse po pirmuju 5 minučiu pavartojus vaisto (vidurkis \pm standartinis nuokrypis)

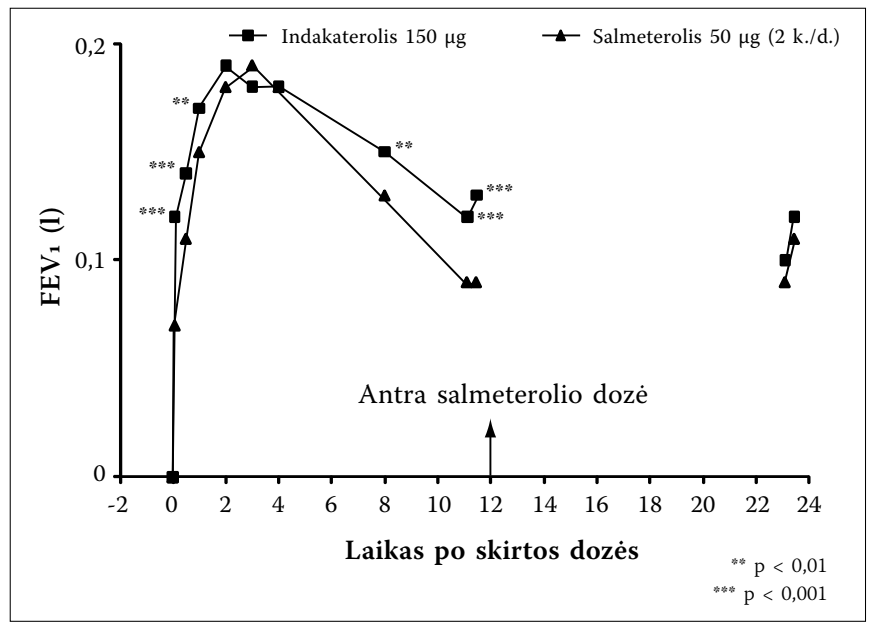

3 pav. $\mathrm{FEV}_{1}$ pokytis indakaterolio $150 \mu \mathrm{g}$ ir salmeterolio $50 \mu \mathrm{g}$ grupese (pirmoji tyrimo diena) $(p<0,05)$

$\mathrm{FEV}_{1}$ pokytis 12 -tą tyrimo savaitę po $5 \mathrm{~min}$. ir po $11 \mathrm{val}$. 45 min. skaičiuojant nuo rytinès vaisto dozès - šis rodiklis indakaterolio grupeje buvo statistiškai reikšmingai didesnis $(\mathrm{p}<0,001)$ nei salmeterolio (koreguotas vidutinis skirtumas $57 \mathrm{ml}$ (PI 35-79)), kaip ir po 24 val. $(60 \mathrm{ml}$ (PI 37-83), p <0,001). Per visus tiriamụjų apsilankymus nustatyta, kad pagal $\mathrm{FEV}_{1}$ indakaterolis veiksmingumu pranoko salmeterolị $(\mathrm{p}<0,001)$, išskyrus antrą apsilankymą (p > 0,05). FEV pokytis indakaterolio $150 \mu \mathrm{g}$ ir salmeterolio $50 \mu \mathrm{g}$ grupése per 24 val. matyti 3 paveiksle. Indakaterolis buvo veiksmingesnis už salmeteroli ir pagal forsuotos gyvybinès talpos (FVC) rezultatus [3].

Dusulys yra vienas pagrindinių simptomų, ribojančių paciento kasdienę veiklą. Dusulio intensyvumui bei dusulio kitimui tam tikru laikotarpiu ir/ar gydymo metu ivertinti dažniausiai naudojamas dusulio kaitos indekso (TDI) klausimynas. Šio tyrimo metu TDI 12-tą savaitę buvo statistiškai reikšmingai didesnis indakaterolio grupèje (vidutinis skirtumas - 0,63 $(0,30-0,97), \mathrm{p}<0,001)$. 
Pacientų skaičius, kuriems TDI padidejo $\geq 1$ balu nuo pradinio, indakaterolio ir salmeterolio grupèse buvo atitinkamai 69,4 proc. ir 62,7 proc. $(\mathrm{p}<0,05)$. Indakaterolio grupèje papildomu salbutamolio inhaliacijų reikèjo 0,18 $(-0,36-0,00)$ purškimo per dieną mažiau nei salmeterolio $(\mathrm{p}<0,05)$; taip pat didesnis procentas dienų, kai salbutamolio nereikejjo iš viso (skirtumas $-4,4(0,6,8,2), \mathrm{p}<0,05)$.

Bendras nepageidaujamų reiškinių dažnumas tarp grupių nesiskyrè [3].

J. F. Donohue su kolegomis atliko atsitiktinių imčių dvigubai aklą tyrimą INHANCE (angl. INdacaterol: vs tiotropium to Help Achieve New COPD treatment Excellence), kuris truko net 26 savaites. Pacientams skirta 150 $\mu \mathrm{g}$ ar $300 \mu \mathrm{g}$ indakaterolio, $18 \mu \mathrm{g}$ tiotropio vieną kartą per dieną arba placebo. Tyrimo tikslas - nustatyti indakaterolio efektyvumą ir palyginti su tiotropiu po 12 ir 26 savaičiu. TDI santykinis padidejjimas nustatytas abiejose indakaterolio grupése lyginant su placebu ir tiotropiu 4, 8 ir 12-tą savaitę. Per visas 26 tyrimo savaites indakaterolio grupeje skubiosios pagalbos vaisto albuterolio poreikis buvo mažesnis nei tiotropio bei placebo grupėse. Paciento bendrajai sveikatai, kasdieniam gyvenimui ir esamai savijautai įvertinti naudojamas šv. Jurgio ligoninės klausimynas (SGRQ). SGRQ bendras rezultatas sumažèjo (pagerejo) lyginant abi indakaterolio dozes su placebu ( $\mathrm{p}<0,01$ ), bet skirtumo lyginant su tiotropiu nebuvo. LOPL paūmèjimų dažnumas indakaterolio $150 \mu \mathrm{g}$ grupejje buvo mažesnis nei placebo (0,67; (95 proc. PI 0,46-0,99); $\mathrm{p}=0,044)$. LOPL paūmèjimų skaičius per metus $150 \mu \mathrm{g}$ ir $300 \mu \mathrm{g}$ indakaterolio, $18 \mu \mathrm{g}$ tiotropio ir placebo grupèse buvo atitinkamai $0,50,0,53,0,53$ ir 0,72 . Śis tyrimas iqrodé, kad gydant indakateroliu plaučių funkcija būna geresnè nei gydant tiotropiu ne tik po 12, bet ir po 26 savaičių [4].

R. Buhl su bendr. INTENSITY (angl. INdacaterol: Toward Establishement of cliNical SuperiorITY) tyrime $150 \mu \mathrm{g}$ indakaterolio efektyvumą lygino su $18 \mu \mathrm{g}$ tiotropio matuodami $F_{1}$ po 23 val. 10 min. ir 23 val. 45 min. po dozès pavartojimo. Nustatyta, kad FVC rodiklis 12-tą tyrimo savaitę pagal šiuos rodiklius nesiskyrè (23 val. 10 min. - 2,83 ir 2,84 l; 23 val. 45 min. - 2,89 ir 2,90 l). Indakateroliu gydytiems pacientams nustatytas didesnis TDI $(2,01 \pm 0,178$ ir 1,43 $\pm 0,078 ; \mathrm{p}<0,001)$ ir SGRQ pagerejimas $(37,1 \pm 0,56$ ir $39,2 \pm 0,55 ; \mathrm{p} 0,001)$. SGRQ rodiklio sumažèjimas daugiau kaip 4 vienetais nuo buvusio pradinio laikomas mažiausiai reikšmingu klinikiniu pokyčiu (MCID), leistinas nuokrypis yra 2,4-5,6. Tyrimo duomenimis, skirtumas nuo pradinio gydant indakateroliu ir tiotropiu buvo atitinkamai $-5,1$ ir $-3,0$. Lyginant su tiotropiu, indakaterolio grupeje klinikinis sveikatos būklès pagerejjimas buvo net 43 proc. didesnis. Indakaterolio grupių pacientams mažiau reikejjo naudoti papildomų salbutamolio inhaliacijų lyginant su placebu ir su tiotropiu, buvo daugiau dienų, kai visai nereikejo vartoti salbutamolio. Taigi indakaterolis pradeda veikti daug greičiau, sumažina dusuli bei pagerina gyvenimo kokybės rodiklius veiksmingiau už tiotropi [5].

Palyginti su placebu, $150 \mu \mathrm{g}$ ir $300 \mu \mathrm{g}$ indakaterolio dozès reikšmingai sumažino LOPL paūmèjimų dažnumą.
52 savaičiu tyrime vieną kartą per dieną vartojamas indakaterolis pailgino laiką iki pirmo LOPL paūmèjimo ir efektyviai sumažino LOPL paūmejjimų dažnumą, nors statistinio skirtumo tarp indakaterolio ir formoterolio nenustatyta [6].

Onbrez $^{\oplus}$ Breezhaler $^{\oplus}$ mažina plaučiu persipildymą oru ir dèl to didina ịkvepiamo oro tūrị fizinio krūvio bei ramybès metu, kliniškai reikšmingai pagerina plaučių funkciją $[3,5,13]$.

\section{SAUGUMAS}

Šalutinių reiškinių, kaip antai: raumenų spazmas, galvos skausmas, tremoras, dažnumas panašus ì placebo grupès. Vartojantiems vaistą didelèmis dozėmis neigiamo poveikio širdies ir kraujagyslių sistemai nebuvo: nepakito širdies susitraukimų dažnis, sistolinis ar diastolinis kraujo spaudimas, nebuvo statistiškai reikšmingų QTc intervalo pokyčių. Pasireiškę šalutiniai reiškiniai buvo panašūs ar net silpnesni nei placebo grupèse, nè vienam tiriamajam nebuvo susiję su vaisto poveikiu $[2,6]$.

H. Worth su bendr. atlikta trijų ilgesnių nei 6 mènesių trukmès trečios fazès klinikinių tyrimų duomenu metaanalizè buvo skirta indakaterolio 150, 300 ir $600 \mu \mathrm{g}$ dozių bei kitų ilgai veikiančių bronchus plečiančių vaistų saugumui širdies ir smegenų kraujagyslèms ištirti [7].

$\mathrm{Nè} \mathrm{vienoje} \mathrm{indakaterolio} \mathrm{grupeje,} \mathrm{lyginant} \mathrm{su} \mathrm{placebu,}$ padidejusios rizikos nenustatyta ( $\mathrm{p}=0,06,0,09$ ir 1,00 atitinkamai 150, 300 ir $600 \mu \mathrm{g}$ grupèse). Vartojusiems tiotropi, lyginant su placebu, santykinè rizika buvo didesné $(\mathrm{p}<0,05)$. O gydant indakateroliu, netgi didinant dozę, santykinè rizika nedidejo. Indakateroli, tiotropi ir placebą vartojusiu pacientuc širdies veiklai stebèti taikyta Holterio stebėsena - ittakos aritmijoms rastis nenustatyta. Metaanalizè parodè, kad indakaterolis nedidina mirties nuo širdies ar smegenų veiklos sutrikimo ir kitų sunkių reakcijų rizikos.

Taigi indakaterolio saugumas artimas placebo ir panašus į kitų ilgo veikimo bronchus plečiančių vaistų. Indakaterolis tikrai gali būti skiriamas nuolatiniam LOPL gydymui [7].

\section{INHALIATORIUS BREEZHALER ${ }^{\circ}$}

Dabar naudojami dviejų tipų inhaliatoriai: slèginiai fiksuotuc dozių ir miltelių. Naudojant slèginius inhaliatorius reikia suderinti ịkvėpimą su vaisto ịpurškimu. Pagrindiniai slèginių fiksuotų dozių inhaliatorių trūkumai yra šie: gaunama nepakankama vaisto dozè dèl netaisyklingos naudojimo technikos (pvz., inhaliatoriaus paspaudimo ir įkvėpimo nesuderinimas, per stipri ikkvejpimo srovė ir kvėpavimas pro nosị) bei šalto freono pojūtis. Nepaisant trūkumų, šie inhaliatoriai vieni populiariausių pasaulyje astmai ir LOPL gydyti, jais naudojasi vaikai, pagyvenę žmonès, pacientai, sergantys lètinèmis ligomis.

Miltelių inhaliatoriai dažniausiai skiriami LOPL pacientams. Naudojant miltelių inhaliatorius kvėpavimo derinti nereikia. Kad i plaučius patektu pakankama vaisto dozé, jo reikia ikvèpti tinkamu stiprumu. Daugumos 
inhaliatoriu specifinis oro pasipriešinimas yra 0,04-0,18 $\mathrm{cm} \mathrm{H}_{2} \mathrm{O} / \mathrm{l} / \mathrm{min}$. Miltelių kapsulès inhaliatorių oro srovès pasipriešinimas mažiausias (apytiksliai $0,07 \mathrm{~cm} \mathrm{H}_{2} \mathrm{O} / \mathrm{l}$ / min.), todèl net sunkios LOPL stadijos pacientams lengviau ịkvėpti, taigi užtikrinamas reikiamos vaisto dozės patekimas i plaučius. Nustatyta, jog pacientas, sergantis vidutine ir sunkia LOPL, vaistą traukia $\geq 60 \mathrm{l} / \mathrm{min}$. greičiu (> $18,9 \mathrm{~cm} \mathrm{H}_{2} \mathrm{O}$ slègiu).

Breezhaler $^{\oplus}$ - mažo pasipriešinimo miltelių kapsulès inhaliatorius. Tai užtikrina tolygu dozès suvartojimą bet kokio sunkumo lètine obstrukcine plaučių liga sergančiam ligoniui Breezhaler ${ }^{\odot}$ inhaliatorius turi ir kitu geru savitumų, ìskaitant taisyklingo ịkvėpimo signalą: ịkvepiant besisukanti kapsule sukuria dūzgimo garsą; taisyklingai įkvèpę pacientai jaučia laktozès skonị; kapsulès yra skaidrios, taigi pacientas gali matyti, ar įkvėpè visą vaisto dozę. Palyginti su aerozoliniais inhaliatoriais, miltelių inhaliatorius lengviau užtaisomas, kapsulei pradurti reikia mažiau jẻgos [9]. Taigi Onbrez ${ }^{\oplus}$ Breezhaler $^{\oplus}$ inhaliatorius yra išskirtinis tuo, kad ịkvèpdami indakateroli iš Onbrez ${ }^{\circ}$ Breezhaler $^{\circ}$ pacientai girdi, jaučia ir mato, kad vaistą vartoja tinkamai.

İkvepiamo vaisto dalelių dydis, kuris iš inhaliatoriaus patenka i plaučius, vadinamas mažu dalelių frakcija arba FPF (mažiau nei $5 \mu \mathrm{m}$ dydžio dalelių frakcija). Vaisto patekimas priklauso ne tik nuo taisyklingos laikysenos ir ikvėpimo, bet ir nuo inhaliatoriaus vidinio pasipriešinimo. Naudojant didelio pasipriešinimo inhaliatorius, reikia daugiau pastangų, kad su įkvėpimo srove patektu reikiamas FPF. K. R. Chapman nustate, jog vidutinis FPF Breezhaler $^{\odot} 150 \mu \mathrm{g}$ grupejje buvo 26,8 proc., o HandiHaler $18 \mu \mathrm{g}$ - 9,8 proc., tai i̇rodo, kad daugiau vaisto patenka i smulkiuosius kvėpavimo takus. LOPL pacientai gydomi ilgo veikimo bronchus plečiančiais vaistais, kurie i plaučius patenka per inhaliatorių. Vidutinis dalelių dydis, lyginant abu inhaliatorius, buvo atitinkamai $3,2 \mu \mathrm{m}$ ir 3,9 $\mu \mathrm{m}$. Vidutinis apskaičiuotasis intratorakalinis vaisto kaupimasis Breezhaler ${ }^{\circ}$ grupeje buvo 31 proc., HandiHaler - 22 proc., o ekstratorakalinis - atitinkamai 57 proc. ir 71 proc. - tai sąlygoja vaisto nuseddimą nosiaryklèje bei šalutines reakcijas. Apklausus pacientus paaiškejjo, jog Breezhaler ${ }^{\circ}$ inhaliatorių kasdien naudoti pageidautų net 61 proc. (HandiHaler - 31 proc.) ( $\mathrm{p}=0,010)$ [8].

Alveolèse lygiųjų raumenų labai maža, todèl daugiau yra beta 2 adrenoreceptorių. Dèl idealaus FPF vaistas patenka net $\mathfrak{i}$ smulkiausius LOPL ligoniu kvèpavimo takus. Tai ịrodo, jog pacientai, sergantys ịvairaus sunkumo LOPL, net ir sunkiausia, gali būti gydomi Breezhaler ${ }^{\circ}$ inhaliatoriumi, nes jis užtikrina reikalingos vaisto dozès patekimą [8].

Onbrez ${ }^{\oplus}$ Breezhaler $^{\oplus}$ vartojamas tik LOPL sergančių suaugusių pacientuc kvėpavimo takų obstrukcijos gydymui. Onbrez Breezhaler $^{\bullet}$ negalima vartoti astmai gydyti, nes duomenu apie ilgalaikio astmos gydymo baigtis nèra. Rekomenduojama kartą per parą Onbrez ${ }^{\odot}$ Breezhaler $^{\oplus}$ inhaliuojama dozè yra viena $150 \mu \mathrm{g}$ kapsulè. Dozę galima didinti tik gydytojo nurodymu. Nustatyta, kad kartą per parą vartojama Onbrez $z^{\infty}$ Breezhaler inhaliatoriumi inhaliuojama viena $300 \mu \mathrm{g}$ kapsulè sukelia papildomą palankų klinikini poveikị dusuliui (ypač sunkia LOPL sergantiems ligoniams). Maksimali kartą per parą vartojama dozė yra $300 \mu \mathrm{g}$.

\section{APIBENDRINIMAS}

2012 metais publikuotoje P. Steiropoulos ir bendr. indakaterolio klinikinių tyrimų apžvalgoje „Indakaterolis: naujas ilgo veikimo beta 2 agonistas LOPL gydymui“, pateikiama ekspertų išvada, kad indakaterolis, vieną kartą per parą vartojamas ilgo veikimo beta 2 agonistas, pasižymintis greita veikimo pradžia (per pirmąsias 5 minutes) ir ilgalaikiu nepertraukiamu poveikiu (24 valandos), visų iki šiol buvusių klinikinių tyrimų metu parodè puikų veiksmingumą, toleravimą ir saugumą [12]. Esamų klinikinių tyrimu duomenimis, Onbrez ${ }^{\odot}$ Breezhaler ${ }^{\ominus}$ yra veiksmingesnis negu kiti inhaliuojamieji beta 2 adrenoreceptoriu agonistai - formoterolis ir salmeterolis, ar net sudetiniai vaistai su inhaliuojamuoju gliukokortikoidu - salmeterolis ir flutikazonas. Be to, Onbrez ${ }^{\oplus}$ Breezhaler $^{\circledR}$ daugeliu aspektu pranašesnis už inhaliuojamąji anticholinergini vaistą tiotropi. Apibendrinant klinikinių tyrimų duomenis galima teigti, kad Onbrez ${ }^{\circ}$ Breezhaler $^{\odot}$ (indakaterolis) yra veiksmingas ir saugus vaistas lètinei obstrukcinei plaučių ligai gydyti, kuris sumažina ligos simptomus ir apsaugo nuo paūmèjimų.

\section{INDACATEROL - THE RAPID AND THE ULTRA-LONG ACTING B2-AGONIST FOR THE TREATMENT OF COPD}

\section{MINDAUGAS VAITKUS \\ DEPARTMENT OF PULMONOLOGY AND IMMUNOLOGY LITHUANIAN UNIVERSITY OF HEALTH SCIENCES}

Keywords: ultra-longacting beta 2 agonist, chronicobstructivepulmonarydisease, inhalation, therapy, indacaterol, Onbrez ${ }^{\circledR}$ Breezhaler ${ }^{\circledR}$

Summary. Indacaterolis a once-daily maintenance broncholdilator treatment of airflow obstruction in adult patients with chronic obstructive pulmonary disease. It has a relatively longer duration of action compared with existing long acting beta 2-agonists and a fast onset of action.

\section{LITERATŪRA}

1. Balint, B., et al., Onset of action of indacaterol in patients with COPD: comparison with salbutamol and salmeterol-fluticasone. Int J Chron Obstruct Pulmon Dis, 2010. 5: p. 311-8.

2. Feldman, G., et al., Efficacy and safety of indacaterol 150 microg once-daily in COPD: a double-blind, randomised, 12-week study. BMC Pulm Med, 2010. 10: p. 11.

3. Korn, S., et al., Indacaterol once-daily provides superior efficacy to salmeterol twice-daily in COPD: a 12-week study. Respir Med, 2011. 105(5): p 719-26.

4. Donohue, J.F., et al., Once-daily bronchodilators for chronic obstructive pulmonary disease: indacaterol versus tiotropium. Am J Respir Crit Care Med, 2010. 182(2): p. 155-62.

5. Buhl, R., et al., Blinded 12-week comparison of once-daily indacaterol and tiotropium in COPD. Eur Respir J, 2011. 38(4): p. 797-803.

6. Ribeiro, M. and K.R. Chapman, Comparative efficacy of indacaterol in chronic obstructive pulmonary disease. Int J Chron Obstruct Pulmon Dis, 2012. 7: p. 145-52.

Kiti literatūros šaltiniai (iš viso 13) redakcijoje. 